\title{
HUBUNGAN HIPERTENSI DENGAN GANGGUAN PENDENGARAN SENSORINEURAL PADA PASIEN RAWAT JALAN DI POLIKLINIK TELINGA HIDUNG TENGGOROKAN DI RSUD PROVINSI NTB TAHUN 2014-2017
}

\author{
Ade Yasinta Dewi*, M. Nurman Hikmallah**, Sukandriani Utami*** \\ Fakultas Kedokteran Universitas Islam Al-Azhar \\ Jl. Unizar No.20 Turida Mataram
}

\begin{abstract}
Hearing loss may be conductive hearing loss and sensorineural hearing loss. All cases of hearing loss, $90 \%$ are sensorineural hearing loss. The most risk of sensorineural hearing loss are the intensity of noise, age, and history of hypertension disease. Studies show that hypertension causes sensorineural hearing loss. this study is an analytical observational with cross sectional study plan. The sample was covering 96 respondents, consisting of 48 sensorineural hearing loss patients and 48 non-sensorineural hearing loss patients.

The study was done using patient medical records at the Ear-Nose-Throat Policlinic of NTB province hospital from 2014 to 2017. Data analysis was performed by contingency coefficient corellation test. The analysis result was significant value $p=0,000<p(0,05)$ which showed their significance or correlation of the conducted study. There is a significant correlation between hypertension and sensorineural hearing loss.
\end{abstract}

Kata Kunci: Hypertension, Hearing Loss.

\section{PENDAHULUAN}

Menurut WHO dan the International Society of Hypertension (ISH), saat ini terdapat 600 juta penderita hipertensi di seluruh dunia, dan 3 juta di antaranya meninggal setiap tahunnya. Tujuh dari setiap sepuluh penderita tersebut tidak mendapatkan pengobatan secara adekuat (Depkes, 2009). Prevalensi hipertensi di Indonesia yang didapat melalui pengukuran pada umur $\geq 18$ tahun sebesar 25,8 persen, tertinggi di Bangka Belitung (30,9\%), diikuti Kalimantan Selatan (30,8\%), Kalimantan Timur $(29,6 \%)$ dan Jawa Barat $(29,4 \%)$. Untuk di Nusa Tenggara Barat prevalensi nya sebesar $24,3 \%$.

$$
\text { Penyakit hipertensi secara }
$$

langsung mempengaruhi aliran pembuluh darah koklea yang mengakibatkan menurunnya transportasi nutrisi dan secara tidak langsung mengakibatkan degenerasi sekunder pada saraf pendengaran. Gangguan proses mendengar dapat terjadi akibat terganggunya fungsi di bagian telinga luar, telinga tengah dan telinga dalam, sehingga seseorang tidak dapat mendengar dengan baik atau tidak dapat mendengar sama sekali.

Gangguan pendengaran dapat berupa tuli konduktif dan tuli sensorineural. Dari semua kasus kehilangan pendengaran, $90 \%$ merupakan tuli sensorineural. Tuli sensorineural adalah tuli yang terjadi karena adanya gangguan pada telinga 
dalam atau pada jalur saraf dari telinga dalam ke otak.

Berdasarkan data Riset Kesehatan

Dasar Prevalensi ketulian Indonesia berdasarkan provinsi, prevalensi gangguan pendengaran tertinggi berdasarkan tes konversasi terdapat di Nusa Tenggara Timur $(3,7 \%)$, dan terendah di Banten (1,6\%). Untuk prevalensi ketulian di Nusa Tenggara Barat yaitu 1,8\%. Berdasarkan data rekam medis laporan indeks penyakit rawat jalan di RSUD Provinsi Mataram tahun 2014-2017, kasus gangguan pendengaran berjumlah 63 orang, untuk gangguan pendengaran sensorineural berjumlah 48 kasus yang dibagi menjadi 1 kasus tuli sensorineural bilateral, 4 kasus tuli sensorineural unilateral dan 43 kasus tuli sensorineural unspesifik.

Penelitian oleh Maria (2009) yang dilakukan di Brazil yang menggunakan 392 sampel tersebut didapatkan bahwa pasien dengan tekanan darah sistolik $\geq$ $140 \mathrm{mmHg}$ dan tekanan darah diastolik $\geq 90 \mathrm{mmHg}$ memiliki kemungkinan lebih besar untuk mengalami peningkatan ambang pendengaran. Hasilnya menunjukkan sampel terbanyak berada pada kategori hilang pendengaran moderat dengan 56,6\% .

Penelitian oleh Marlina dkk (2016), berdasarkan hasil analisis uji multivariat variabel yang paling berpengaruh dan menjadi faktor risiko gangguan pendengaran sensorineural oleh faktor intensitas kebisingan, usia, dan riwayat penyakit hipertensi adalah sebesar $97,6 \%$, adapun sisanya $(2,4 \%)$ terdapat faktor lain di luar faktor penelitian.

Adanya hipertensi akan mengakibatkan iskemia yang disebabkan spasme pembuluh darah atau karena proses arteriosklerosis sehingga lumen dari pembuluh darah menjadi sempit, dan otot dari lapisan media menjadi atrofi. Penyempitan lumen pembuluh darah ini menyebabkan penurunan perfusi jaringan dan penurunan kemampuan sel otot untuk beraktivitas, selanjutnya akan terjadi hipoksia jaringan yang menyebabkan kerusakan sel-sel rambut. Mekanisme inilah yang dianggap sebagai penyebab gangguan pendengaran sensorik pada hipertensi. Pada penelitian binatang dibuktikan terdapat peninggian rata-rata kehilangan sel rambut koklea pada tikus diabetik hipertensi jika dibandingkan degan tikus diabetik normotensi dan tikus non diabetik normotensi.

Pada hipertensi endolimfatik seperti pada penyakit meniere dapat terjadi tinitus pada nada rendah atau tinggi sehingga terdengar bergemuruh atau berdengung. Gangguan ini disertai dengan tuli sensorineural dan vertigo. Gangguan vaskuler koklea terminal yang terjadi pada pasien yang stres 
akibat gangguan keseimbangan endokrin, seperti menjelang menstruasi, hipometabolisme atau saat hamil, dapat timbul tinitus dan gangguan tersebut akan hilang bila keadaanya normal kembali.

Pada hipertensi kronik dapat terjadi trombosis, emboli, vasospasme, yang tentunya dapat terjadi dengan adanya faktor lipid yang kurang baik pula. Reduksi dari oksigenasi pada koklea sangat berpengaruh pada hambatan vaskularisasi ini. Akibat adanya hambatan pada vaskularisasi koklea ini, dapat terjadi iskemia koklea yang pada akhirnya dapat mengakibatkan terjadinya kehilangan pendengaran tuli sensorineural dan tinnitus.

Hingga saat ini belum terdapat penelitian di Mataram tentang adanya hubungan Hipertensi dengan Gangguan Pendengaran Sensorineural.

Berdasarkan data-data di atas maka penulis ingin mengetahui hubungan Hipertensi dengan Gangguan Pendengaran Sensorineural di Poliklinik Telinga-Hidung-Tenggorokan RSUD Propinsi NTB tahun 2014-2017

\section{METODELOGI PENELITIAN}

Penelitian ini bersifat analitik observasional dengan menggunakan rancangan penelitian cross sectional. Dalam penelitian ini teknik pengambilan sampel yang digunakan adalah teknik simple random sampling.

\section{Pengambilan Sampel}

Populasi dalam penelitian ini adalah seluruh pasien yang datang ke Poliklinik Telinga-Hidung-Tenggorokan RSUD Propinsi NTB dengan diagnosis Tuli Sensorineural pada Tahun 2014 2017. Pengambilan sampel dilakukan secara acak dengan sistem mengundi nama dari semua populasi dan setiap nama yang keluar akan dijadikan sampel. Dalam penelitian ini didapatkan 96 responden.

Kriteria inklusi dari penelitian ini, yaitu ; Pasien yang mengunjungi Poliklinik Telinga-Hidung-Tenggorokan RSUD berusia 20-65 tahun 2014-2017, Pasien yang mengalami gangguan pendengaran sensorineural sebagai kelompok kasus, Pasien yang mengalami gangguan pendengaran selain sensorineural sebagai kelompok kontrol

\section{HASIL DAN PEMBAHASAN}

Karakteristik Sampel Berdasarkan Usia

Tabel 1. Karakteristik Sampel Berdasarkan Usia pada pasien SNHL

\begin{tabular}{ccc}
\hline Usia & Jumlah & $\begin{array}{c}\text { Persentase } \\
(\mathbf{\%})\end{array}$ \\
\hline $20-35$ & 17 & 35,4 \\
Tahun & & \\
$35-50$ & 16 & 33,3 \\
Tahun & & \\
$50-65$ & 9 & 18,8 \\
Tahun & 6 & 12,5 \\
\hline
\end{tabular}




\begin{tabular}{|c|c|c|c|}
\hline \multicolumn{2}{|c|}{ Total } & 48 & 100 \\
\hline Tabel & \multicolumn{3}{|c|}{$\begin{array}{l}\text { Berdasarkan Usia pada pasier } \\
\text { non SNHL. }\end{array}$} \\
\hline \multicolumn{2}{|c|}{ Usia } & Jumlah & $\begin{array}{c}\text { Persentase } \\
(\%)\end{array}$ \\
\hline \multicolumn{2}{|c|}{$\begin{array}{l}20-35 \\
\text { Tahun }\end{array}$} & 21 & 43,8 \\
\hline \multicolumn{2}{|c|}{$\begin{array}{l}35-50 \\
\text { Tahun }\end{array}$} & 15 & 31,3 \\
\hline \multicolumn{2}{|c|}{$50-65$} & 11 & 22.9 \\
\hline \multicolumn{2}{|c|}{$\underset{>65}{\text { Tahun }}$} & 1 & 2.1 \\
\hline \multicolumn{2}{|c|}{ Total } & 48 & 100 \\
\hline
\end{tabular}

Karakteristik Sampel Berdasarkan

Jenis Kelamin

Tabel 3. Karakteristik Sampel Berdasarkan Jenis Kelamin pada pasien SNHL.

\begin{tabular}{ccc}
\hline Jenis Kelamin & Jumlah & $\begin{array}{c}\text { Persentase } \\
(\boldsymbol{\%})\end{array}$ \\
\hline Laki & 25 & 52.1 \\
Perempuan & 23 & 47,9 \\
\hline Total & 48 & 100 \\
\hline
\end{tabular}

Tabel 4. Karakteristik Sampel Berdasarkan Jenis Kelamin pada pasien non SNHL.

\begin{tabular}{ccc}
\hline $\begin{array}{c}\text { Jenis } \\
\text { Kelamin }\end{array}$ & Jumlah & $\begin{array}{c}\text { Persentase } \\
(\boldsymbol{\%})\end{array}$ \\
\hline Laki & 28 & 58.3 \\
Perempuan & 20 & 41,7 \\
\hline Total & 48 & 100 \\
\hline
\end{tabular}

\section{Karakteristik Sampel Berdasarkan}

\section{Kategori Tekanan Darah}

Tabel 5. Karakteristik Sampel Berdasarkan Kategori Tekanan Darah pada pasien SNHL.

\begin{tabular}{ccc}
\hline $\begin{array}{c}\text { Tekanan } \\
\text { Darah }\end{array}$ & Jumlah & $\begin{array}{c}\text { Persentase } \\
(\mathbf{\%})\end{array}$ \\
\hline Normal & 18 & 37,5 \\
Hipertensi & 30 & 62,5 \\
\hline Total & 48 & 100 \\
\hline
\end{tabular}

Tabel 6. Karakteristik Sampel Berdasarkan Kategori Tekanan Darah pada pasien non SNHL.

\begin{tabular}{lcc}
\hline $\begin{array}{c}\text { Tekanan } \\
\text { Darah }\end{array}$ & Jumlah & $\begin{array}{c}\text { Persentase } \\
(\boldsymbol{\%})\end{array}$ \\
\hline Normal & 35 & 72,9 \\
Hipertensi & 14 & 27,1 \\
\hline \multicolumn{1}{c}{ Total } & 48 & 100 \\
\hline Hubungan & Hipertensi & dengan \\
Gangguan & \multicolumn{2}{c}{ Pendengaran } \\
Sensorineural & pada & Pasien Rawat \\
Jalan di Poliklinik & Telinga-Hidung- \\
Tenggorokan RSUD & Propinsi NTB \\
tahun 2014-2017
\end{tabular}

Tabel 7. Hubungan Hipertensi dengan Gangguan Pendengaran Sensorineural pada Pasien Rawat Jalan di Poliklinik Telinga-HidungTenggorokan RSUD Propinsi NTB tahun 2014-2017.

\section{Tuli}

\begin{tabular}{|c|c|c|c|c|c|c|}
\hline \multirow{3}{*}{$\begin{array}{c}\text { Hiper } \\
\text { tensi }\end{array}$} & \multicolumn{4}{|c|}{$\begin{array}{c}\text { Tuli } \\
\text { Sensorineural }\end{array}$} & \multirow{2}{*}{\multicolumn{2}{|c|}{ Jumlah }} \\
\hline & \multicolumn{2}{|c|}{ Ya } & \multicolumn{2}{|c|}{ Tidak } & & \\
\hline & $\mathrm{N}$ & $\%$ & $\mathrm{~N}$ & $\%$ & $\mathrm{~N}$ & $\%$ \\
\hline Ya & 30 & 31,3 & 13 & 13,5 & 43 & 44,8 \\
\hline Tidak & 18 & 18,8 & 35 & 36,5 & 53 & 55,2 \\
\hline $\begin{array}{r}\text { Jumla } \\
\mathrm{h}\end{array}$ & 48 & 50 & 48 & 50 & 96 & 10 \\
\hline
\end{tabular}

Dari 96 orang sampel yang diteliti, terdapat $43(44,8 \%)$ pasien dengan hipertensi dan $53(55,2 \%)$ pasien dengan tekanan darah normal. Dari 43 pasien dengan hipertensi, $30 \quad(31,3 \%)$ diantaranya mengalami tuli sensorineural, dan 13 (13,5\%) pasien dengan hipertensi tidak mengalami tuli sensorineural. Sedangkan dari 53 pasien 
dengan tekanan darah normal, 18 $(18,8 \%)$ pasien diantaranya mengalami tuli sensorineural, dan 35 (36,5\%) pasien tidak mengalami tuli sensorineural

Dari tabel di atas didapatkan hasil bahwa yang mengalami tuli sensorineural lebih banyak berasal dari pasien dengan hipertensi bila dibandingkan dengan pasien dengan tekanan darah normal

Berdasarkan dari hasil koefisien contingency (C) antara hipertensi dengan kejadian tuli sensorineural didapatkan nilai signifikansi (P-value) sebesar 0,000. Karena p-value $<\alpha$ $(0,000<0,05)$ maka dapat diambil kesimpulan bahwa H0 ditolak yang berarti bahwa ada hubungan hipertensi dengan kejadian tuli sensorineural di Poli THT RSUD Provinsi NTB periode Tahun 2014 sampai 2017

Berdasarkan Tabel 4.1, dapat diketahui pasien yang menderita tuli sensorineural yang datang berobat ke Poli THT RSUD Provinsi NTB lebih banyak pada pada rentang usia antara 20-50 tahun. Hal ini menunjukan bahwa bertambahnya usia dapat berhubungan dengan terjadinya tuli sensorineural . Hal ini sejalan dengan penelitian Evy (2005) bahwa faktor usia berkaitan dengan fungsi pendengaran karena faktor ketuaan (presbiakusis), dimana sudah dapat ditemukan pada usia di atas 40 Tahun dan banyak dijumpai pada usia 60-65 tahun.

Berdasarkan data Kementerian Kesehatan Republik Indonesia (2013), prevalensi gangguan pendengaran atau tuli meningkat selaras pertambahan umur. Prevalensi tuli pada umur 25-34 tahun (1\%) dan melonjak ketika umur 55-64 tahun (5,7\%), 65-74 tahun $(17,1 \%)$ serta umur lebih dari 75 tahun $(36,6 \%)$.

Berdasarkan tabel 4.3, dapat diketahui pasien yang menderita tuli sensorineural yang datang berobat ke Poli THT RSUD Provinsi NTB tidak terdapat perbandingan signifikan antara jenis kelamin laki-laki maupun wanita, yang menunjukan bahwa ketulian jenis sensorineural dapat menyerang siapa saja.

Berdasarkan analisis korelasi pada tabel 4.7 antara hipertensi dengan kejadian tuli sensorineural dan sesuai dengan perhitungan odd ratio pada tabel 4.8 diatas. Setelah dilakukan uji statistik menggunakan uji koefisien contingency yang hasilnya menunjukkan p-value sebesar 0,000. Hal ini menunjukkan bahwa p-value $<0,05$ sehingga H0 ditolak yang berarti didapatkan hasil bahwa hipertensi mempunyai hubungan signifikan dengan kejadian tuli sensorineural pada pasien rawat jalan Poli THT RSUD Provinsi NTB

Hal ini sejalan dengan penelitian yang dilakukan oleh Moonika (2013) 
Sebagian besar pasien hipertensi yang mengalami gangguan pendengaran, terbanyak pada pasien yang mengalami hipertensi selama lebih dari 9 tahun. Hingga saat ini belum terdapat penelitian yang membuktikan bahwa lama hipertensi berpengaruh terhadap gangguan pendengaran. Hasil penelitian ini juga belum dapat menjelaskan hubungan antara lama hipertensi dengan gangguan pendengaran karena responden yang diperoleh di poli sebagian besar mengalami lama hipertensi lebih dari 9 tahun. Beberapa penelitian juga menunjukkan bahwa hipertensi merupakan faktor yang mempercepat degenerasi organ pendengaran yang berkaitan dengan penuaan Penelitian lain menjelaskan bahwa gangguan pendengaran yang terjadi dengan penuaan berhubungan dengan insufisiensi mikrosirkulatori yang terjadi akibat oklusi pembuluh darah yang disebabkan oleh emboli, perdarahan atau vasospasme, dan ini terjadi karena sindrom hiperviskositas

\section{KESIMPULAN}

Berdasarkan hasil dan pembahasan mengenai hubungan Hipertensi dengan Gangguan Pendengaran Sensorineural pada Pasien Rawat Jalan di Poliklinik Telinga-Hidung-Tenggorokan RSUD Propinsi NTB tahun 2014-2017, dapat diambil kesimpulan sebagai berikut. atau mikroangiopati yang disebabkan oleh diabetes atau hipertensi dan melalui mekanisme histopatologi yang dapat menyebabkan gangguan pendengaran sensorineural.

Menurut Prihantara,

Insiden gangguan pendengaran pada hipertensi sangat bervariasi. Terdapat perbedaan signifikan gangguan pendengaran pada kelompok hipertensi dibandingkan yang tidak. Selain itu ditemukan insidens tinitus lebih tinggi pada kelompok hipertensi.

Hipertensi merupakan penyakit metabolik yang berhubungan dengan komplikasi klinik, kecacatan, dan kematian. Lebih dari setengah kematian pasien yang berumur 50 ke atas berhubungan dengan penyakit kardiovaskular dan $80 \%$ diantaranya hipertensi. Beberapa penyakit yang sering dan dapat menjadi komplikasi hipertensi yaitu stroke, penyakit hati, gangguan ginjal dan pembuluh darah perifer.

Dari 96 orang sampel yang diteliti, terdapat $43(44,8 \%)$ pasien dengan hipertensi dan $53(55,2 \%)$ pasien dengan tekanan darah normal. Dari 43 pasien dengan hipertensi, $30 \quad(31,3 \%)$ diantaranya mengalami tuli sensorineural, dan 13 (13,5\%) pasien dengan hipertensi tidak mengalami tuli sensorineural. 
Berdasarkan dari hasil koefisien contingency (C) antara hipertensi dengan kejadian tuli sensorineural didapatkan nilai signifikansi (P-value) sebesar 0,000. Karena p-value $<\alpha$ $(0,000<0,05)$ maka dapat diambil kesimpulan bahwa H0 ditolak.

\section{UCAPAN TERIMAKASIH}

Melalui kesempatan ini penulis mengucapkan terimaksih yang sebesarbesarnya kepada : dr. M. Nurman $\mathrm{H}$, M.Sc. Med., Sp. THT-KL Selaku Pimbimbing I yang telah memberikan petunjuk, arahan, dan bimbingan bagi penulis selama menempuh pendidikan dan dr. Sukandriani Utami selaku pembimbing II yang dengan sabar dan ihlas meluangkan waktu untuk membimbing penulis selama proses penyelesaian tulisan ini.

\section{DAFTAR PUSTAKA}

Riskesdas, 2013, Prevalensi gangguan pendengaran dan ketulian penduduk umur $\geq 5$ tahun sesuai tes konversasi menurut karakteristik Indonesia 2013 , Riset Kesehatan Dasar, Badan Penelitian Dan Pengembangan Kesehatan Kementerian Kesehatan RI Tahun 2013, (Http://Www.Depkes.Go.Id/Resou rces/Download/General/Hasil\%20 riskesdas\%202013.Pdf), Diakses 20 Oktober 2017.

Marlina Sinta, Suwondo Ari, Jayanti Siswi ,2016, Analisis Faktor Risiko Gangguan Pendengaran Sensorineural Pada Pekerja Pt. X Semarang, Jurnal Kesehatan
Masyarakat (E-Journal) Volume 4, Nomor 1, Januari 2016 (Issn: 2356-3346) (http://ejournals1.undip.ac.id/index.php/jkm). Diakses 20 Oktober 2017.

Laughlin, ME. 2015, Sensorineural Hearing Loss. Diakses: (www.hearing-loss-review.com). Diakses 20 Oktober 2017.

Maria Fernanda, Lopes AC. 2009, Relation between arterial hypertension and hearing loss. Intl. Arch. Otorhinolaryngol. 2009;13:63-68

Prihantara, YS. 2002, Kurnag Pendengaran Sensorineural Pada Penderita Diabetes Melitus. Semarang.. Diunduh dari http://eprints.undip.ac.id/12246/ Diakses 20 Oktober Riskesdas, 2013, Hipertensi/Tekanan Darah Tinggi, Riset Kesehatan Dasar, Badan Penelitian Dan Pengembangan Kesehatan Kementerian Kesehatan RI Tahun 2013,

(Http://Www.Depkes.Go.Id/Resou rces/Download/General/Hasil\%20 riskesdas\%202013.Pdf), Diakses 20 Oktober 2017.

Soepardi, Arsyad, 2007, Buku Ajar Ilmu Kesehatan Telinga Hidung Tenggorokan Kepala \& Leher; Edisi keenam. Balai Penerbit FKUI. Jakarta.

Mathur Neeraj N 2017, Sudden Hearing Loss, Vardhman Mahavir Medical College and Safdarjung Hospital; Professor, Guru Gobind Singh Indraprastha University and Delhi University, India. (https://emedicine.medscape.com/ article/856313-overview) Diakses 20 Oktober 2017.

Moonika, 2013, Pengaruh Hipertensi Terhadap Ambang Pendengaran, Bagian / Smf Telinga Hidung Tenggorok-Bedah Kepala Leher Fakultas Kedokteran, Universitas Sam Ratulangi, B. 